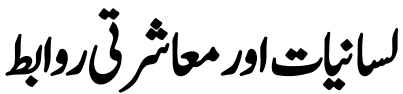

\section{Linguistics and Social Connections}

Arif Hussain

Ph.D Scholar, Department of Urdu, National University of Modern Languages(NUML) Islamabad, Pakistan

\section{KE Y W O R D}

Language Importance

Language Types

Mother Tongue

Regional Language

Official Language

Sign Language

\section{A T ES}

Received 18-07-2021

Accepted 03-09-2021

Published 19-09-2021

\section{A B S T RA C T}

Language is fundamental to any society. It is through language that we can communicate our thoughts to others. The more a language is used, the more it will develop. There are many types of languages including mother tongue, regional language, religious language, official language, business language, national language, international language and so on. When speaking, language and ascent are not taken into consideration, but there is a need to be careful while writing. People who cannot speak a language use specific gestures or symbols to convey their point of view to others. Therefore, we can say that the use of language began as soon as man came into this world.

DOI: https://doi.org/10.54064/negotiations.v1i2.16

QR CODE

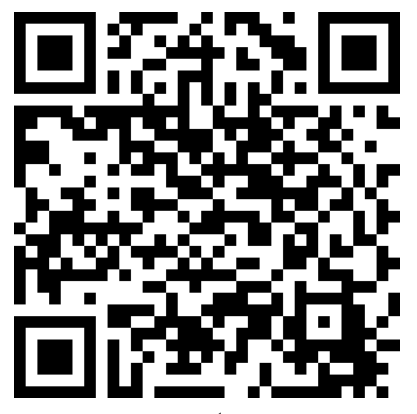

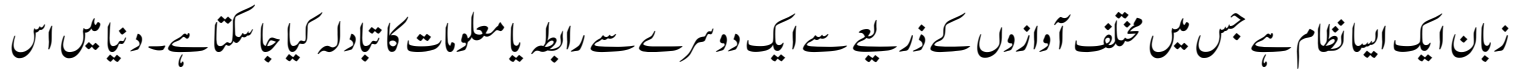

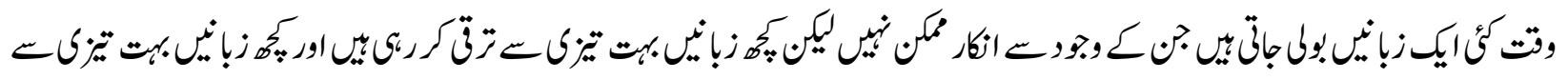

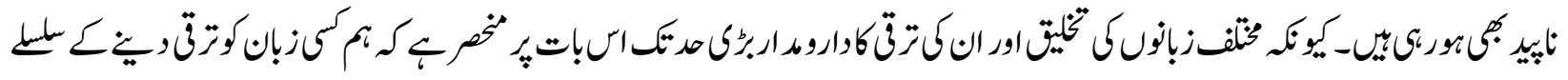

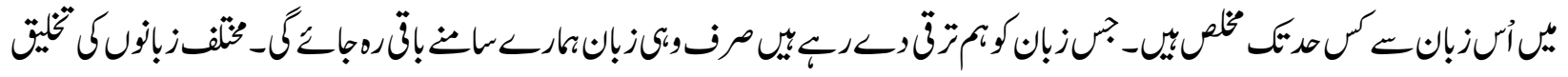




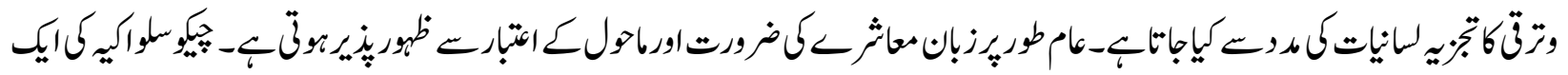

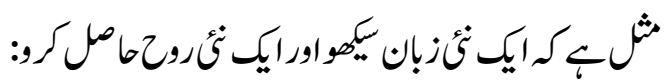
Learn a new language and get a new soul

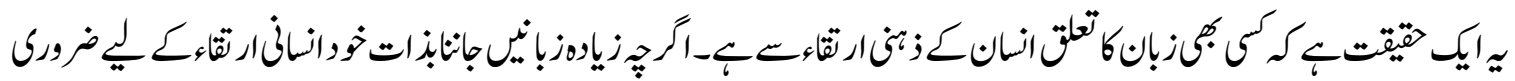

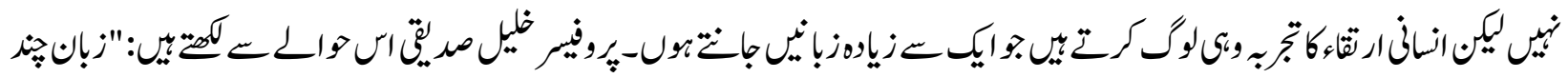

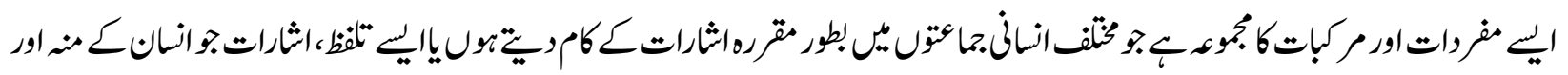

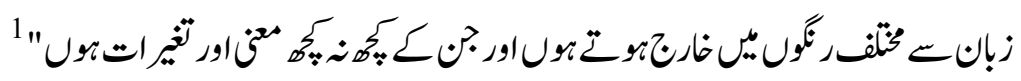

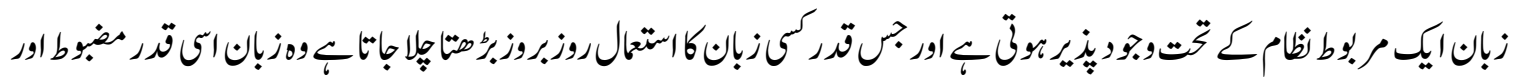

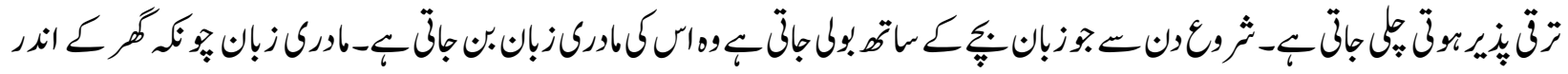

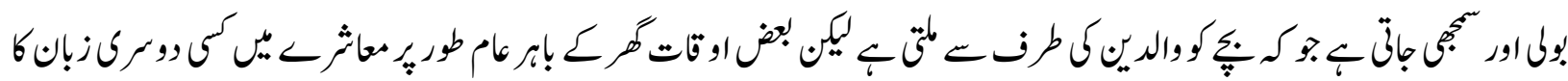

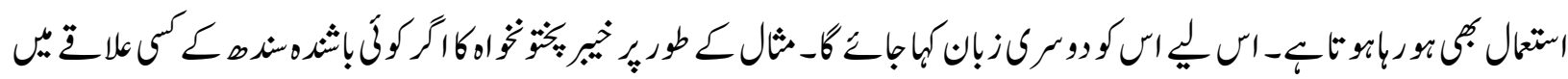

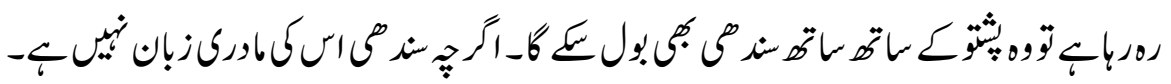

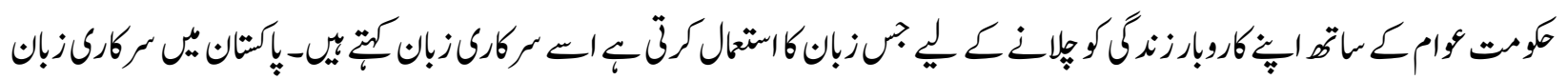

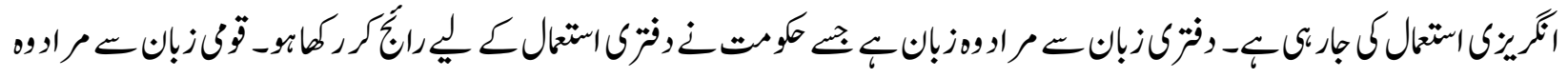

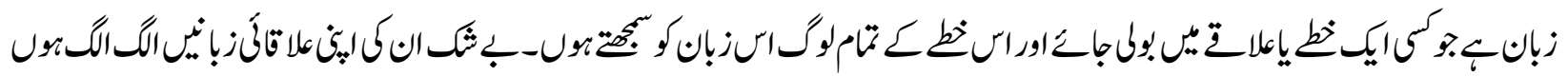

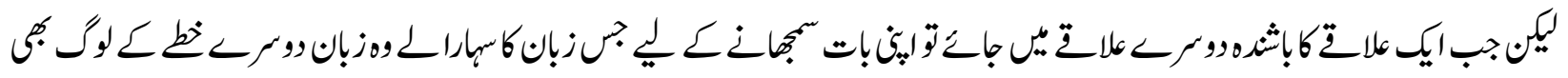

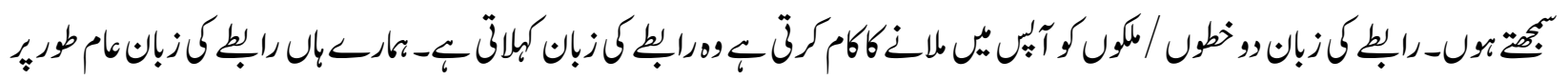

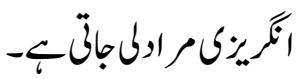

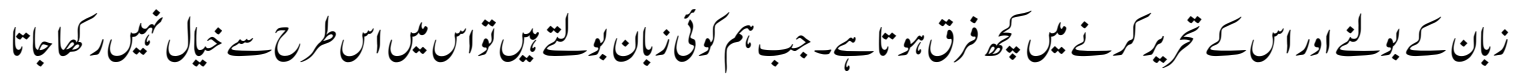

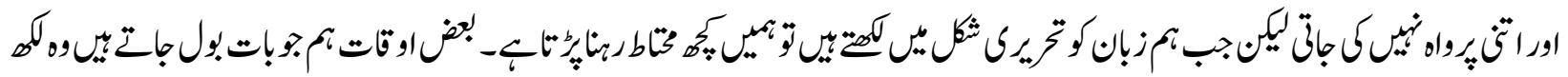
-

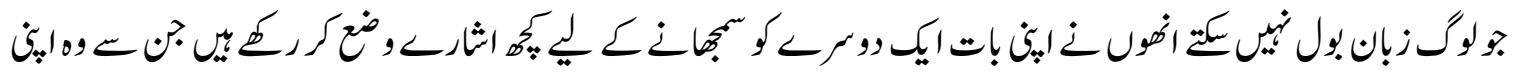

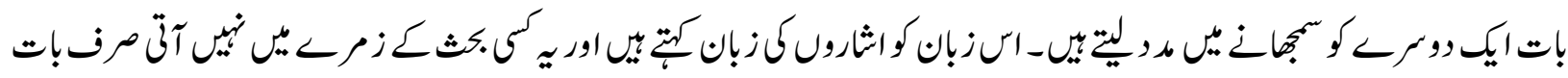

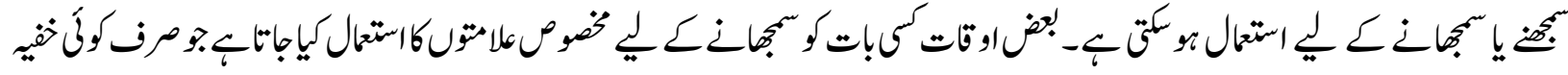

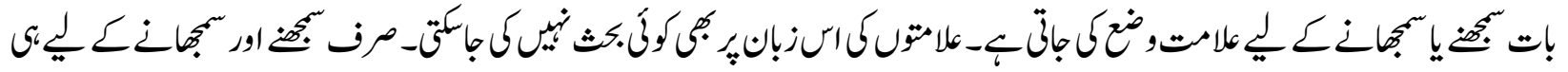

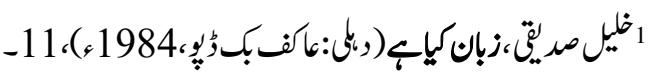




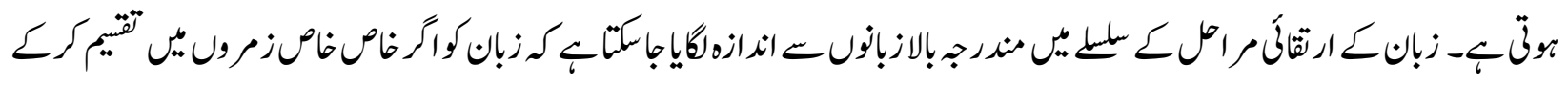

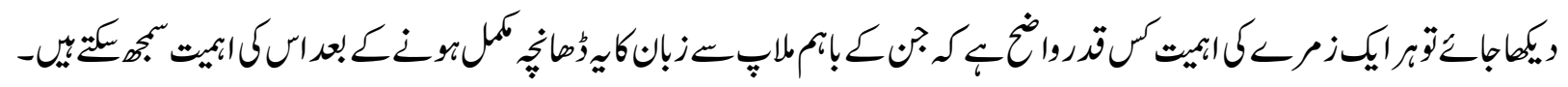

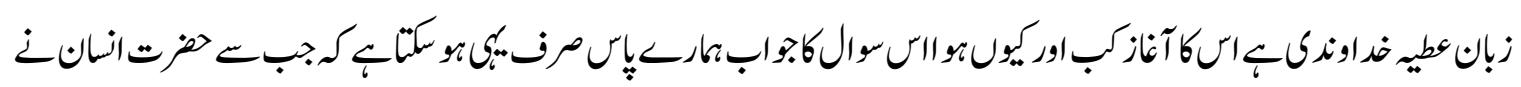

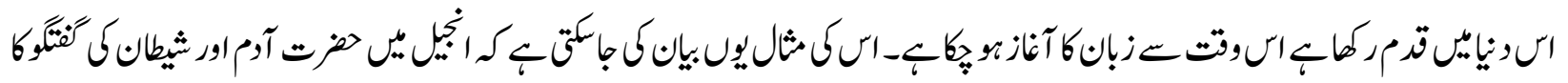

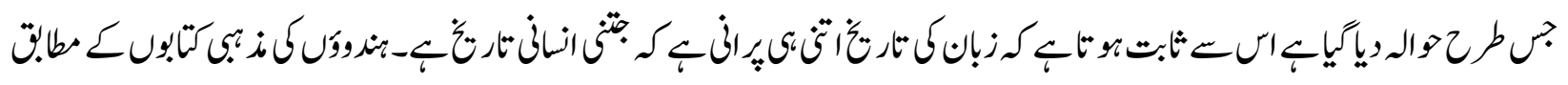

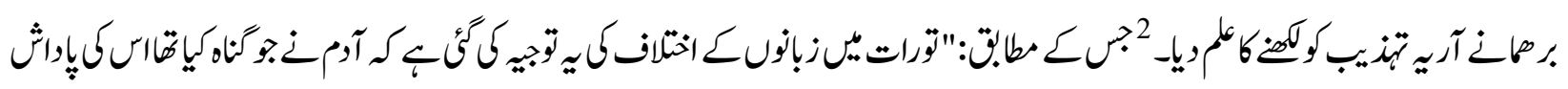

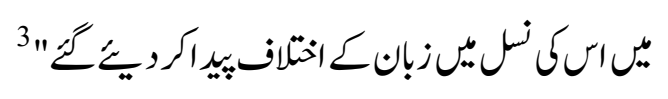

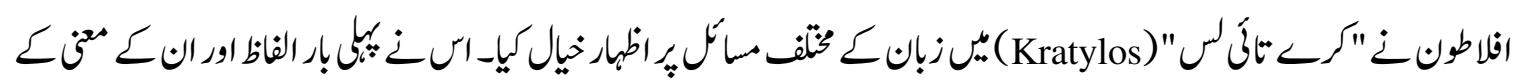

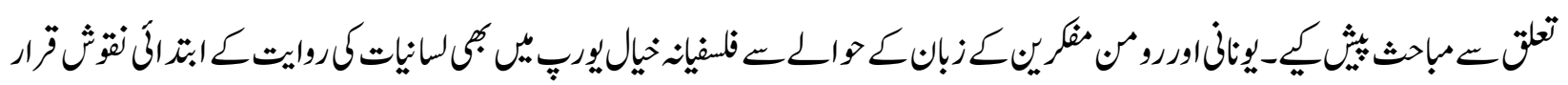
وي بإكتِنيل

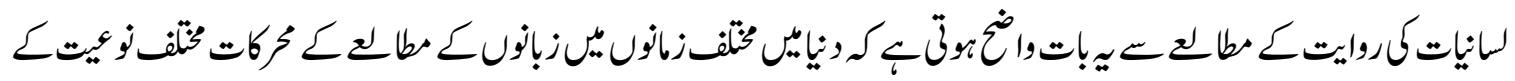

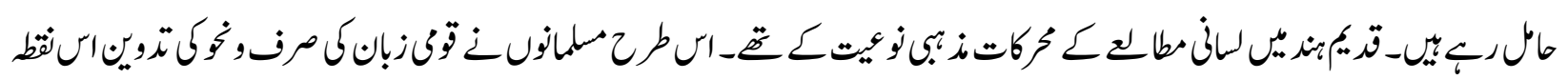

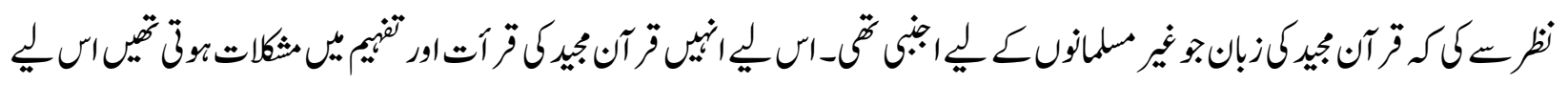

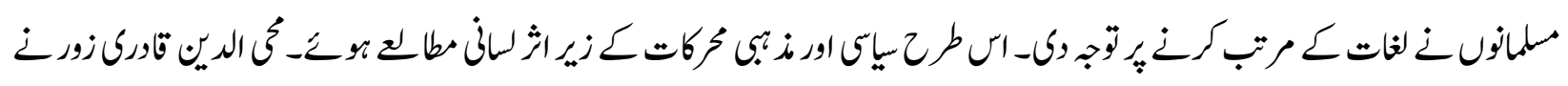

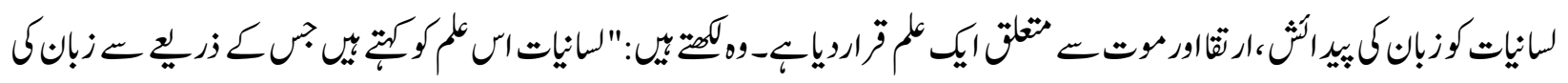

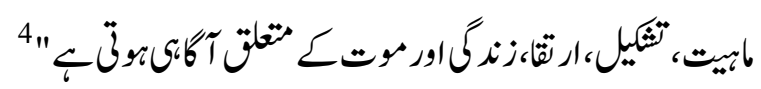

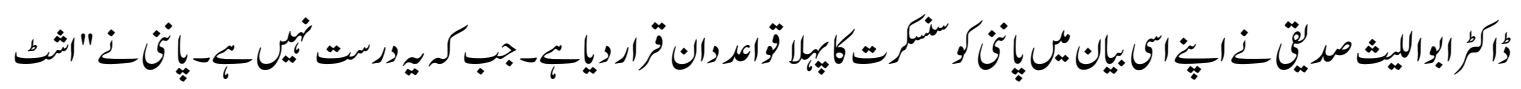

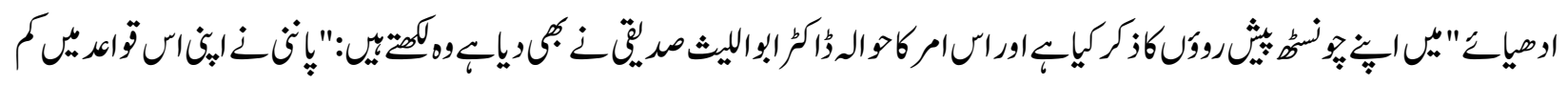

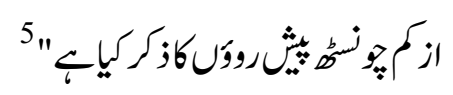

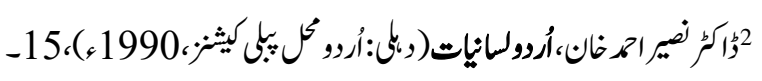

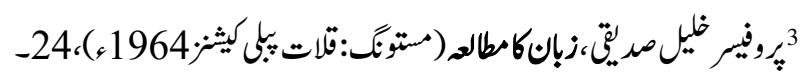

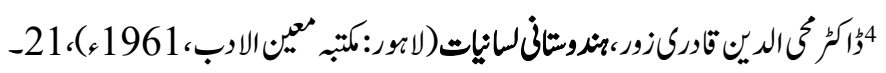

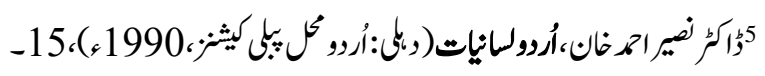




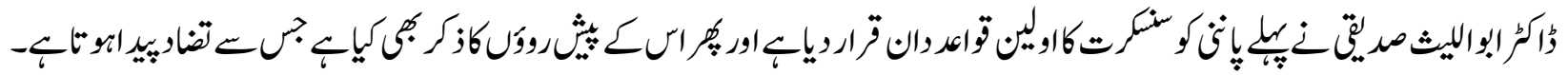

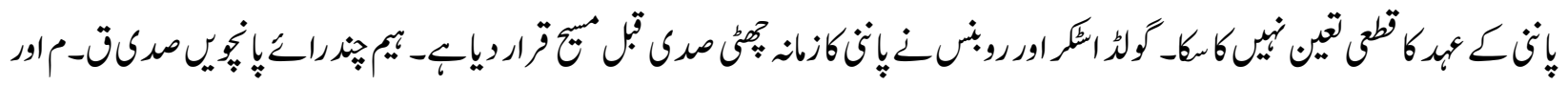

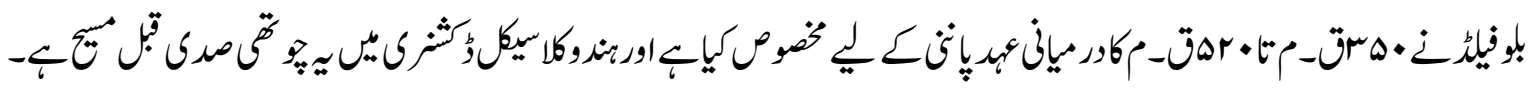

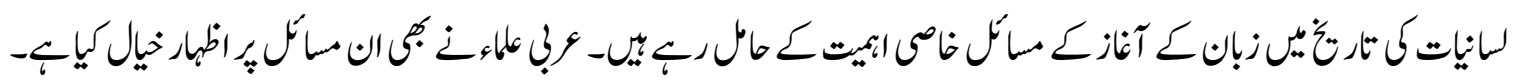

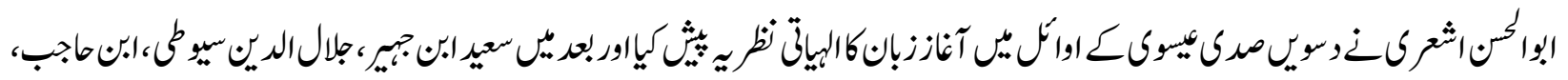

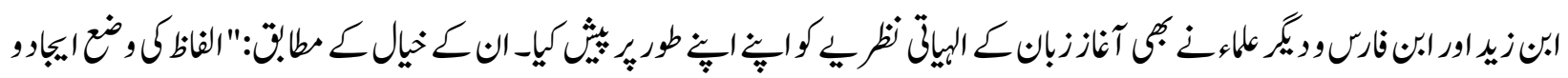

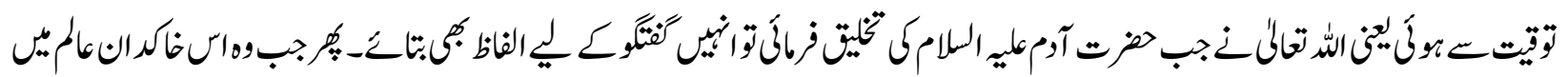

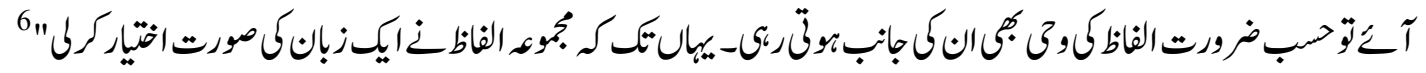

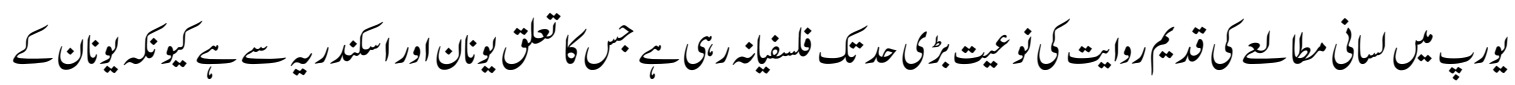

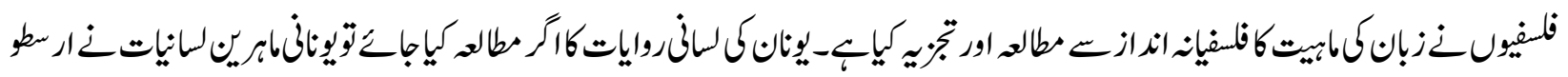

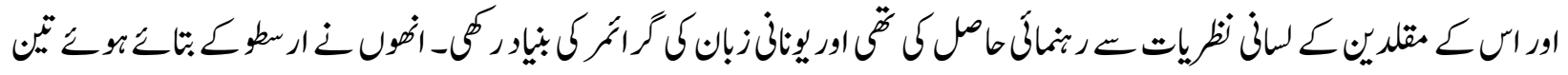

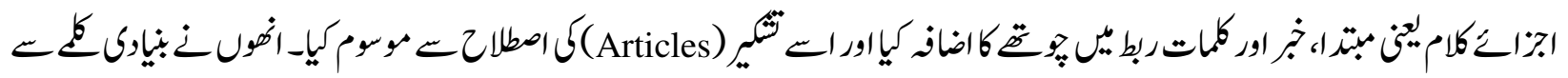

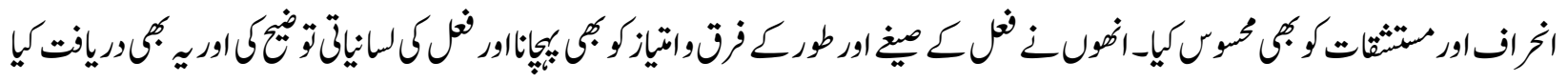

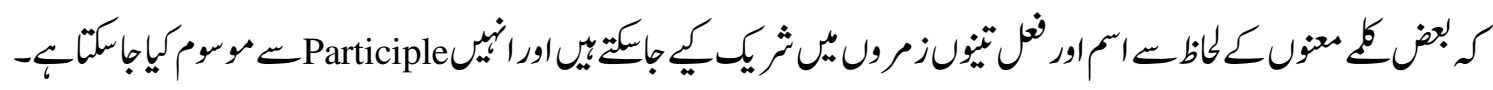

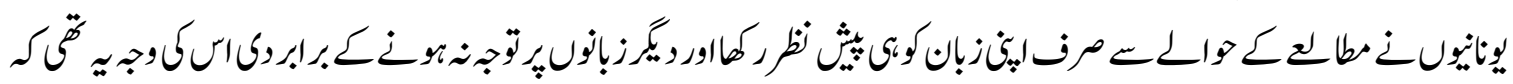

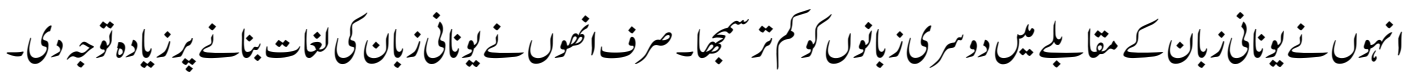

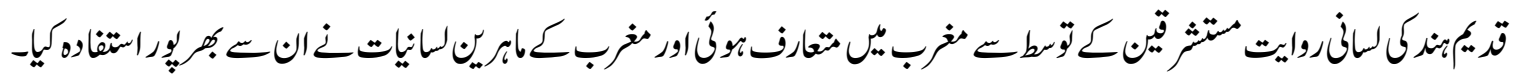

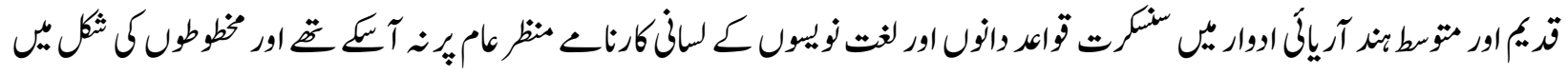

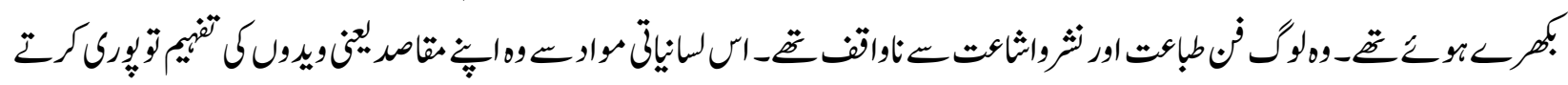

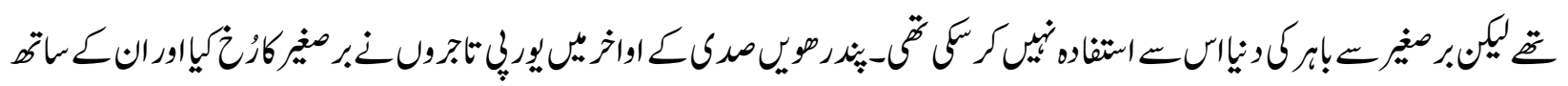

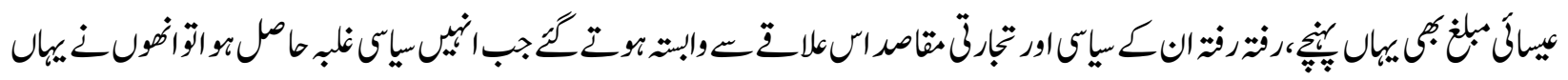

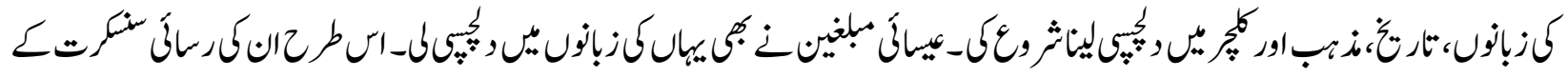

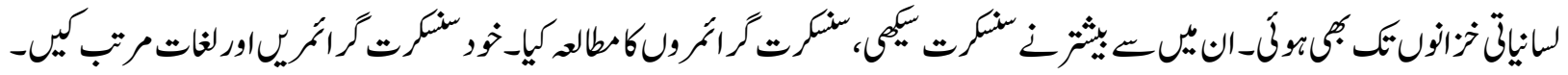

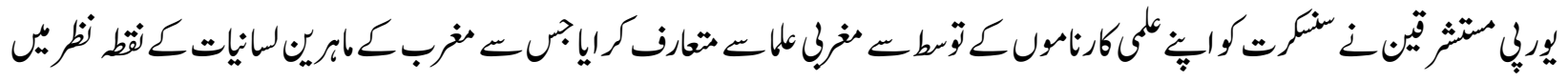

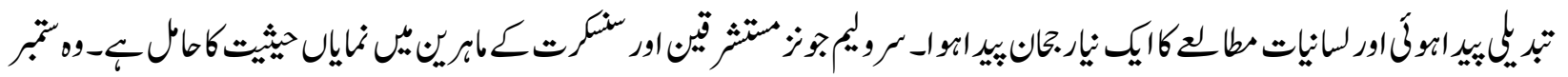




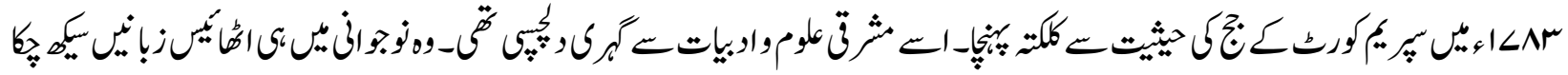

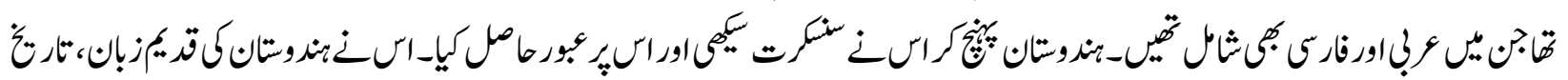

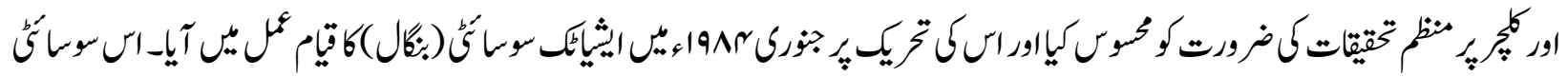

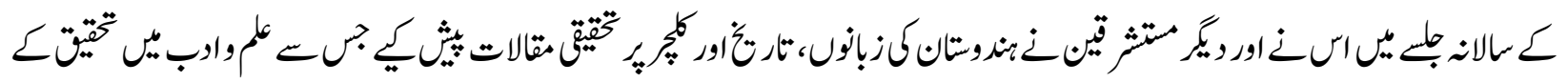

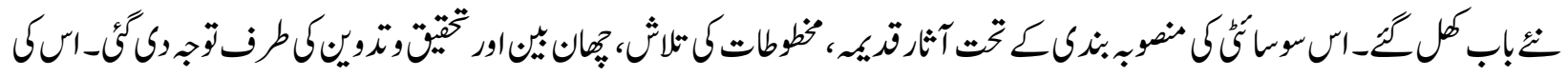

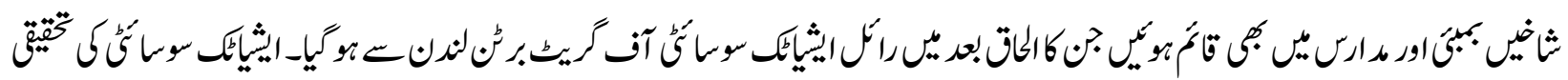

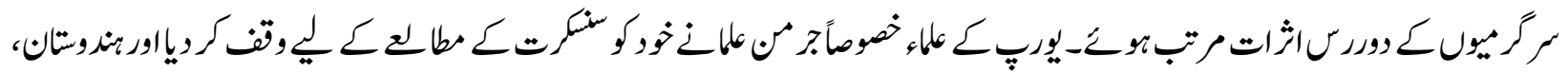

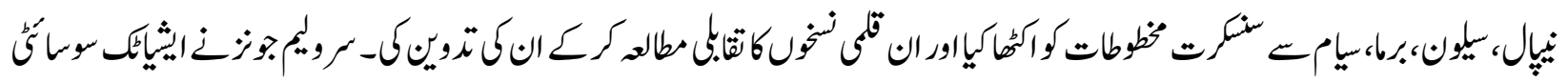

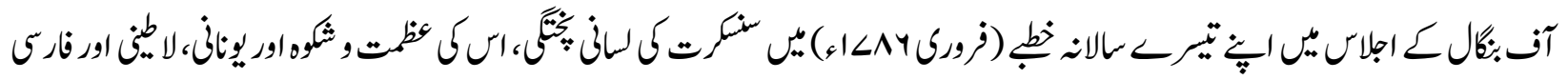

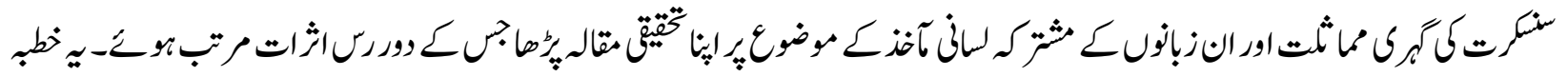

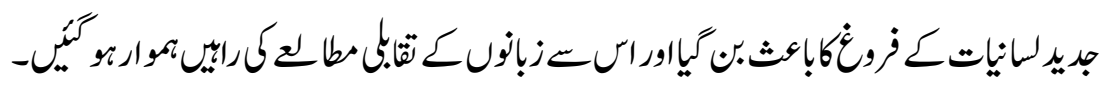

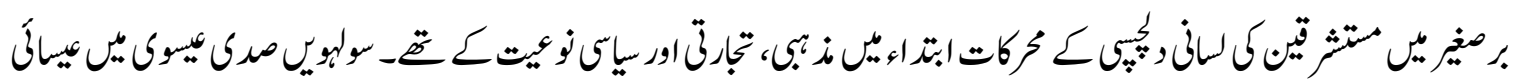

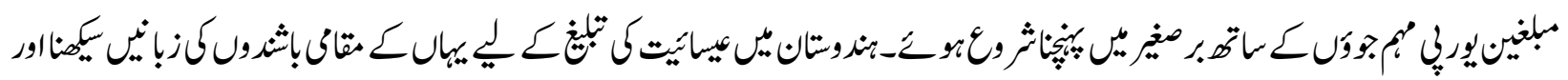

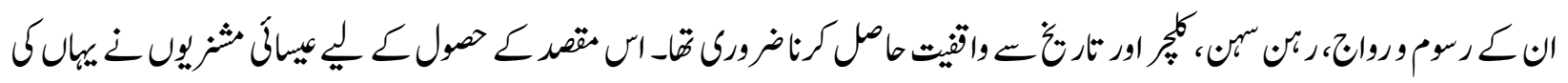

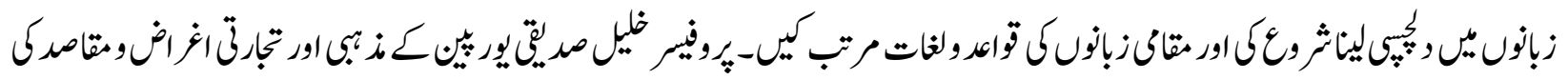

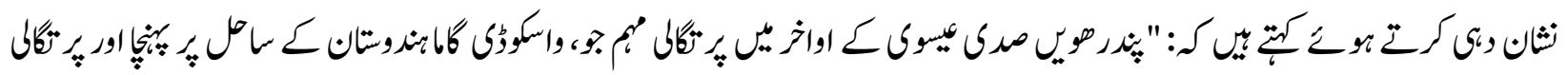

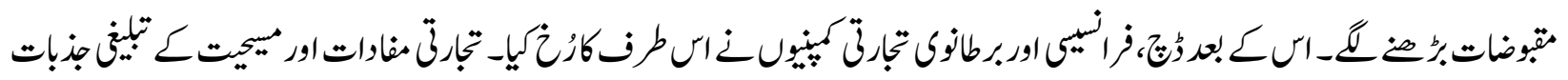

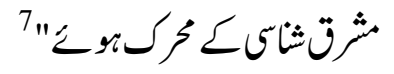

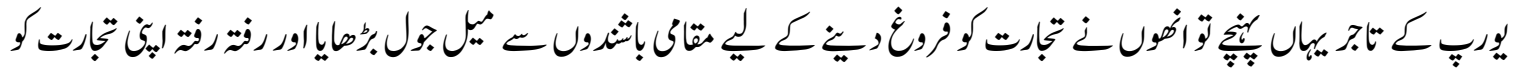

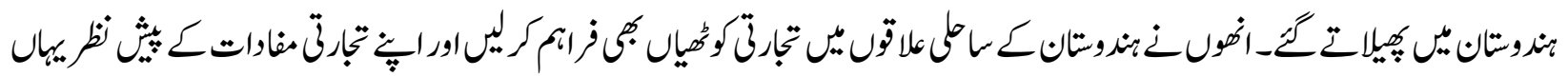

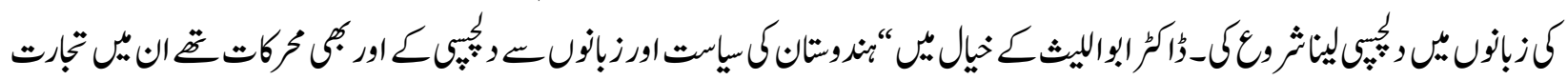

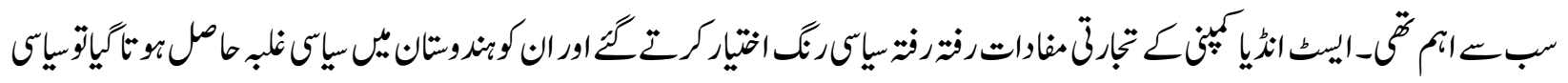

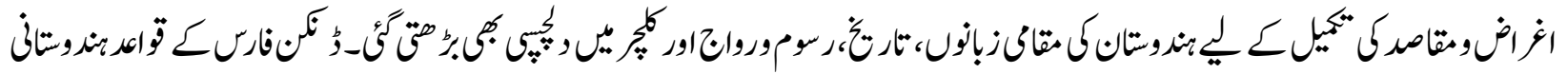

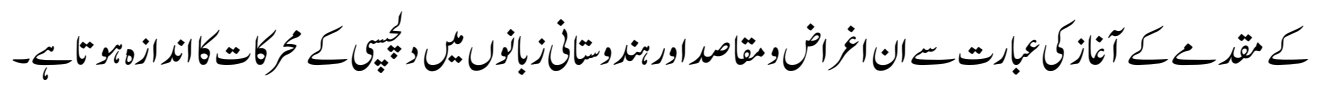




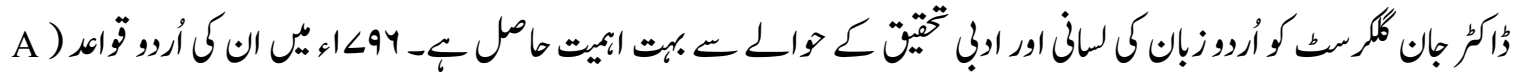

CGrammar of the Hindustani Language

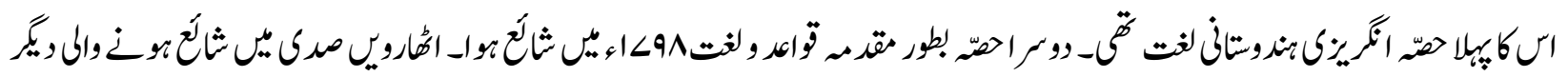

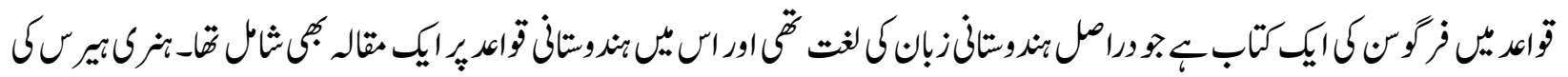

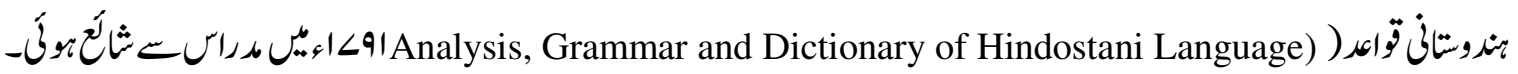

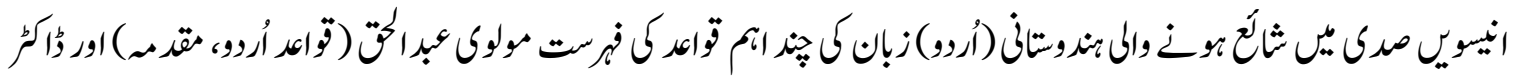

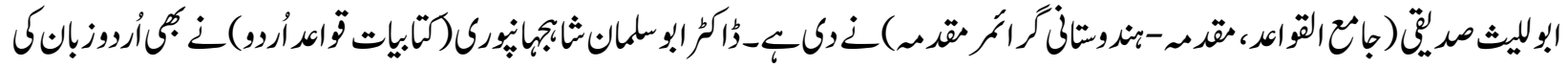

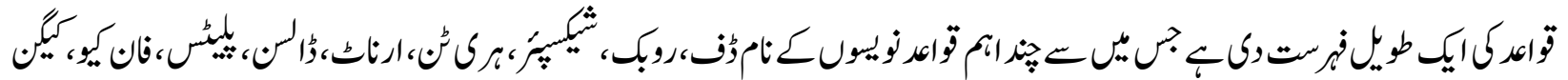
, نيرهيّ-

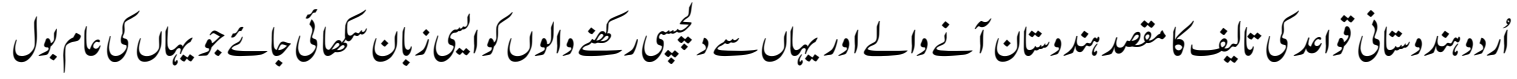

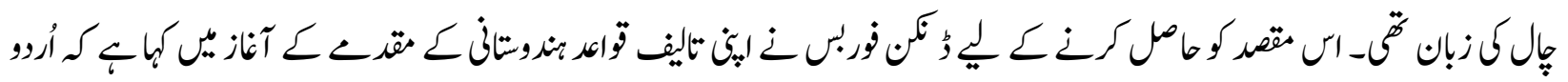

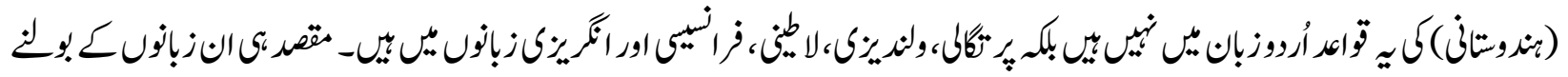

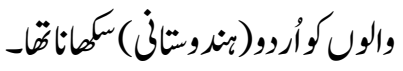

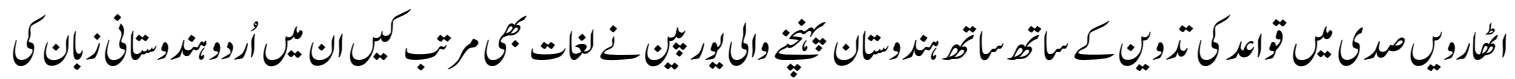

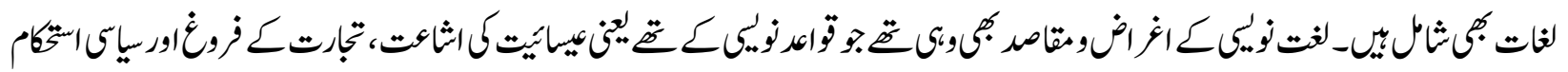

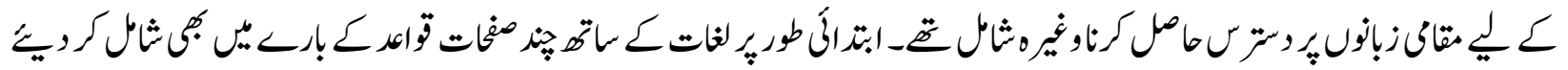

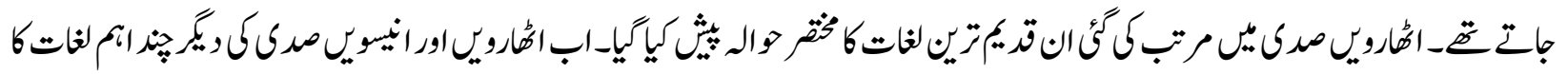

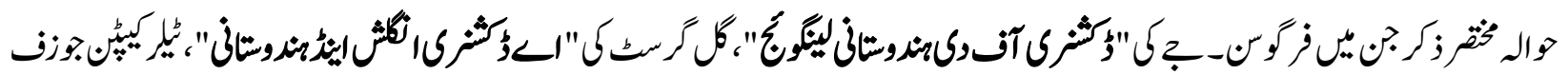

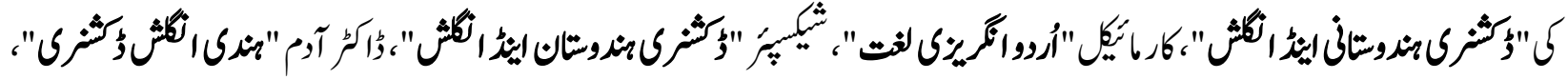

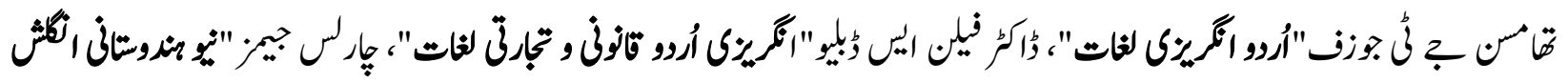

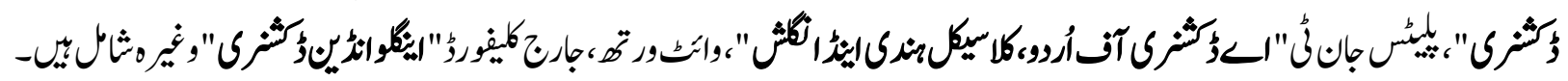

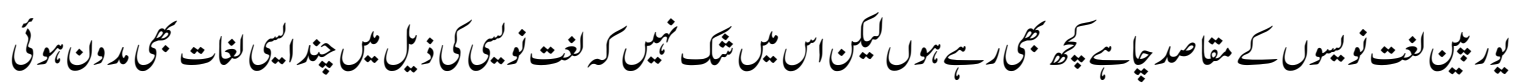

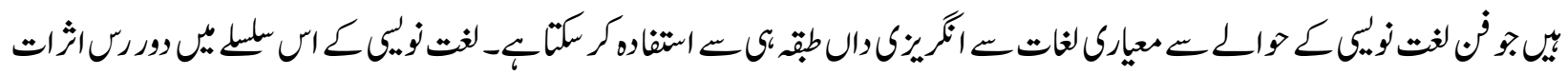

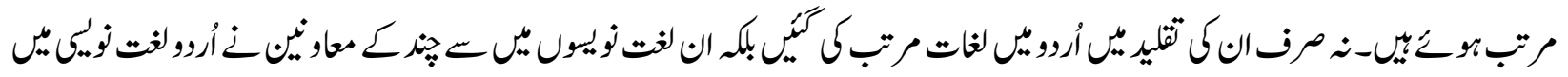

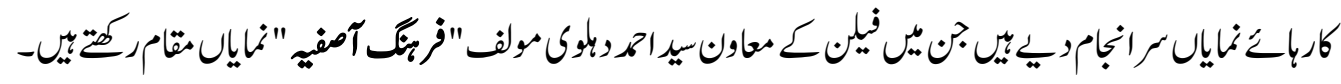

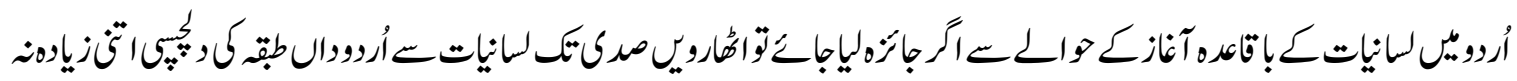

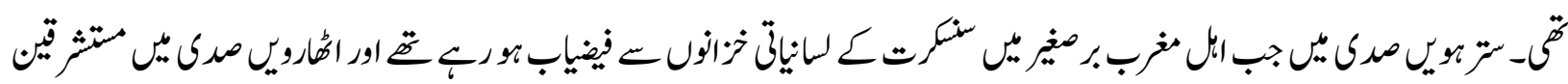




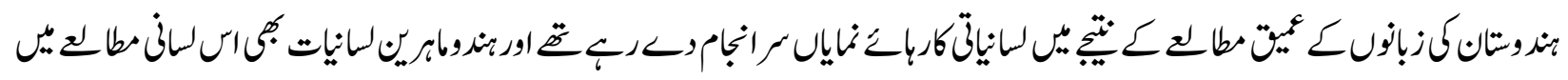

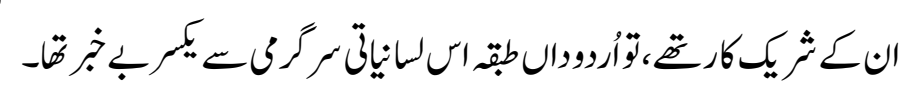

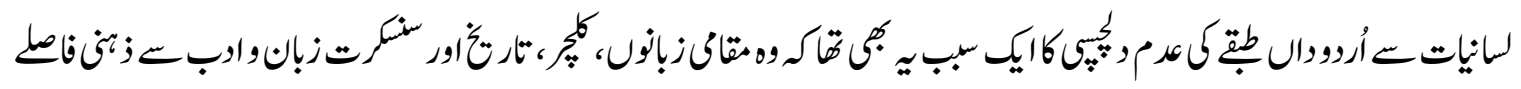

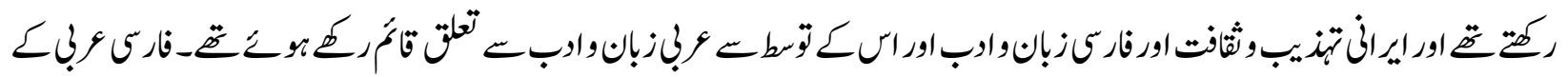

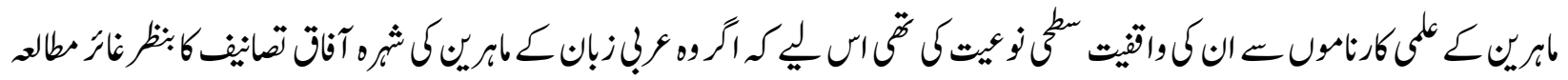

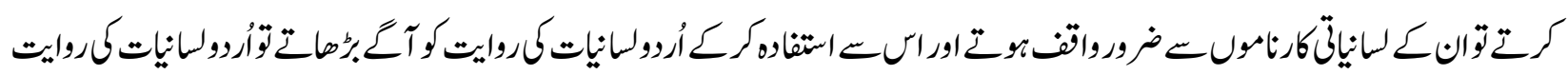

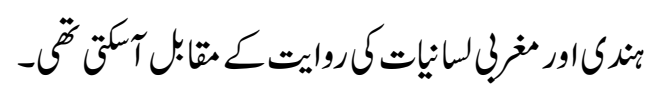

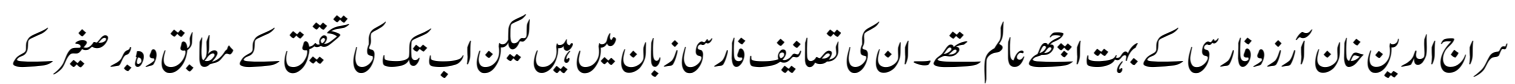

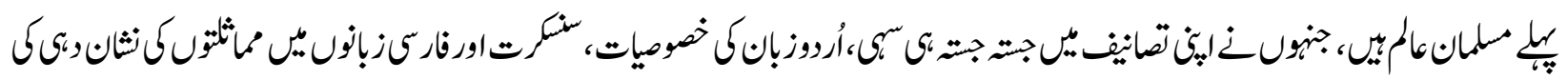

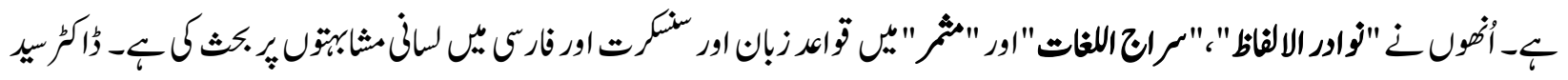

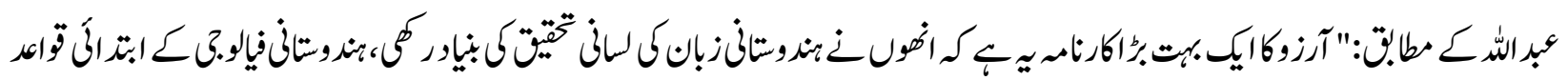

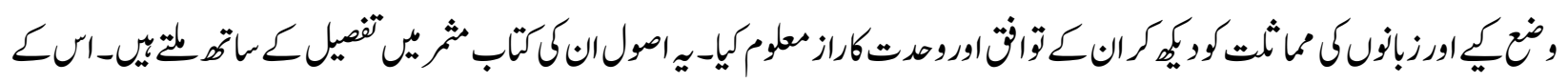

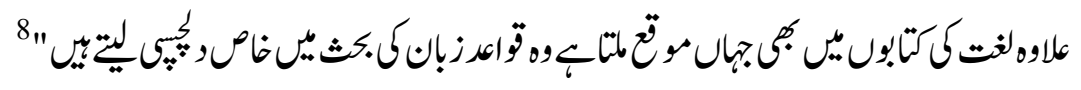

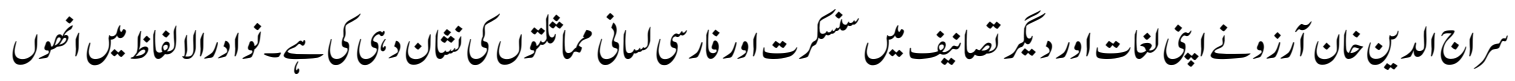

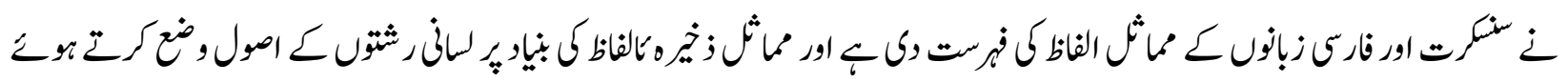

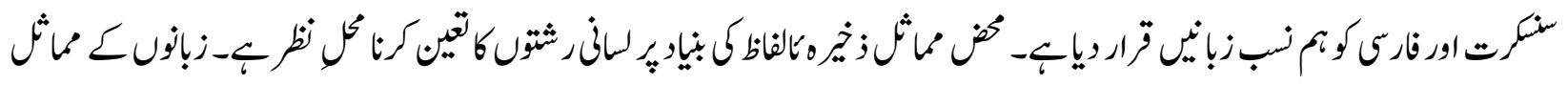

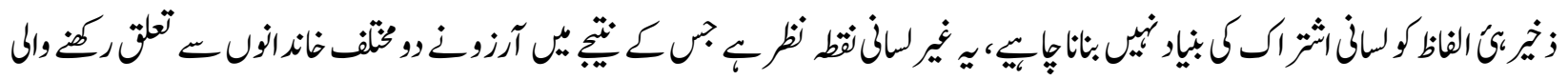

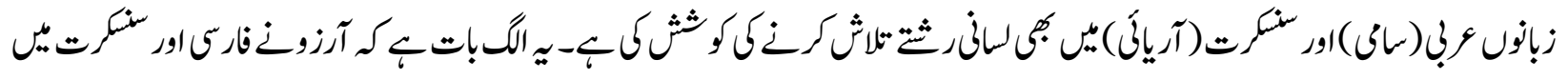

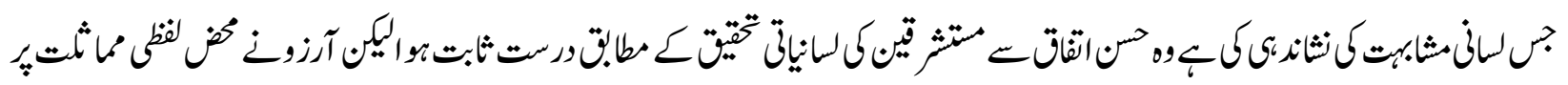

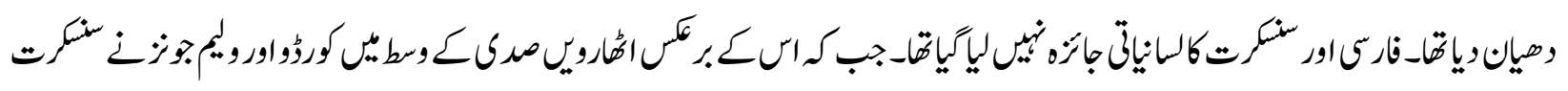

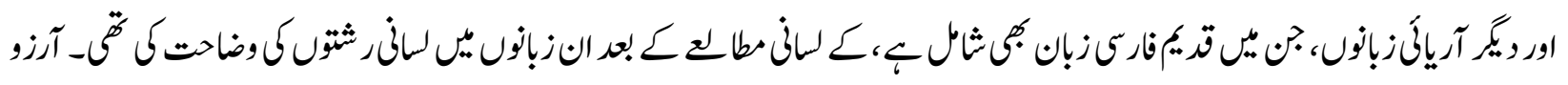

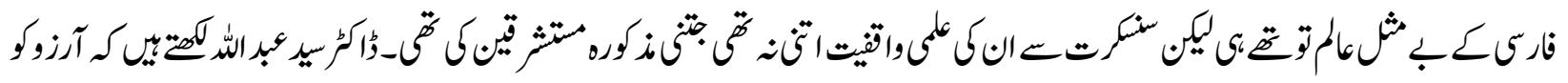

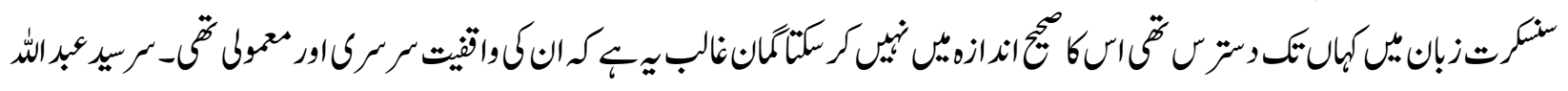

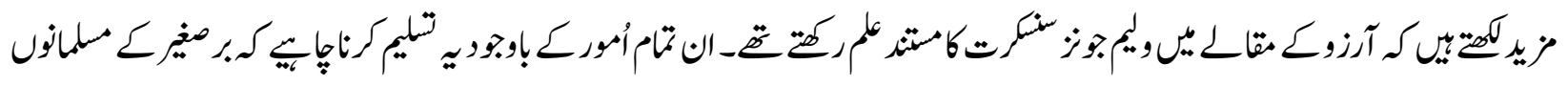

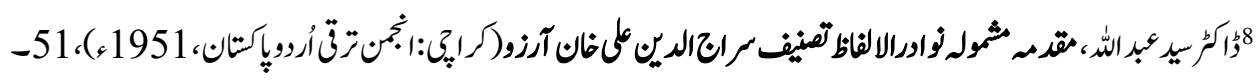




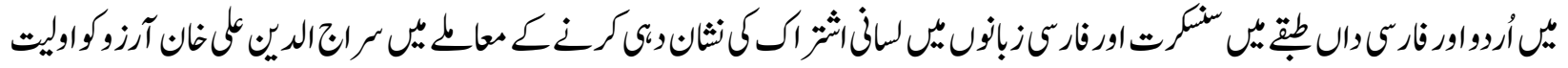

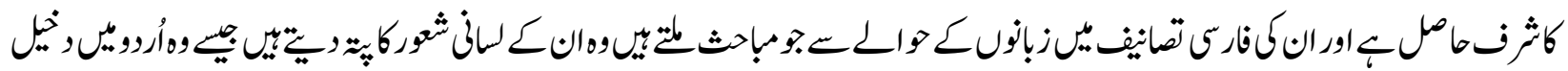

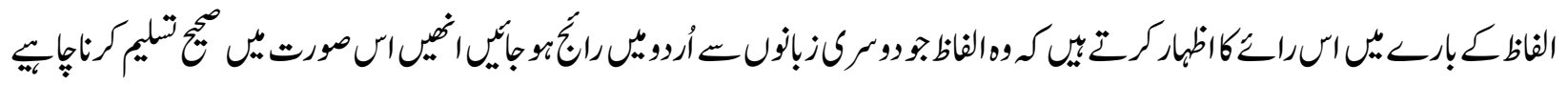

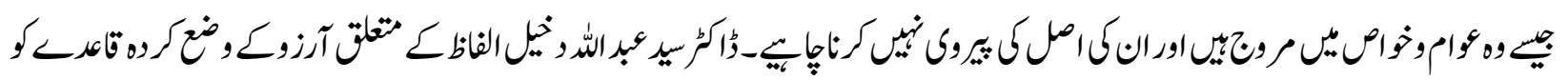

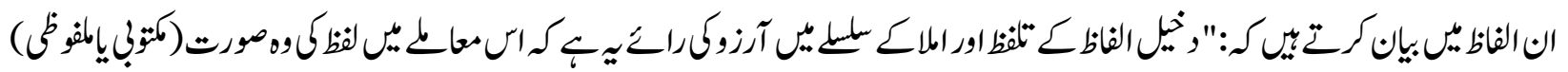

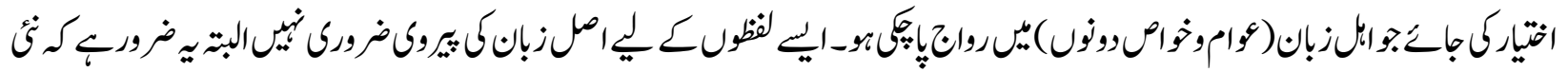

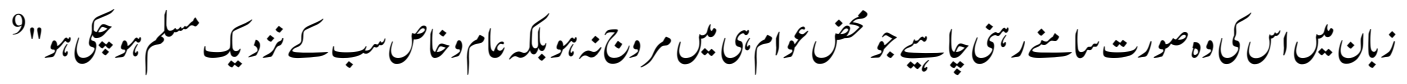

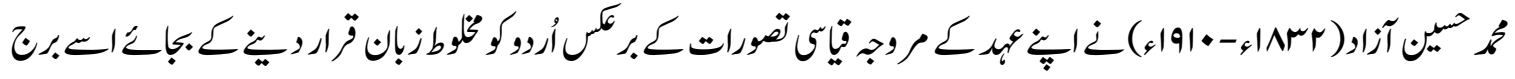

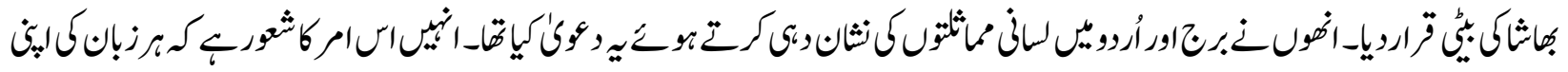

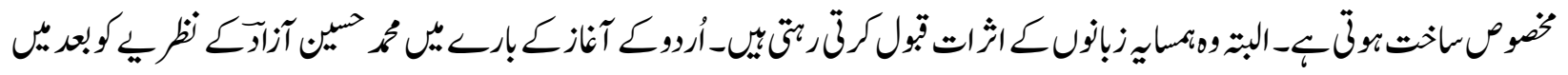

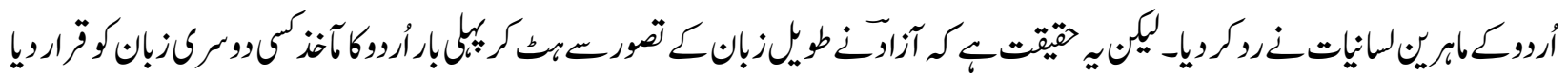

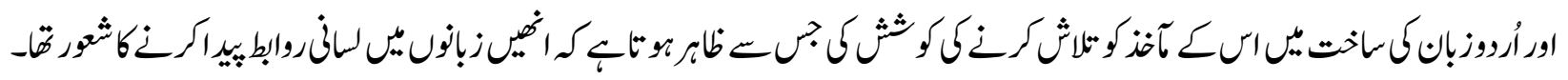

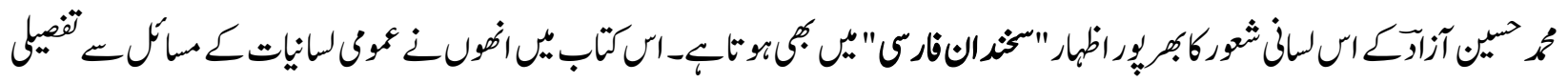

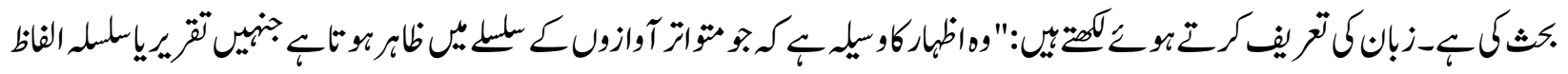

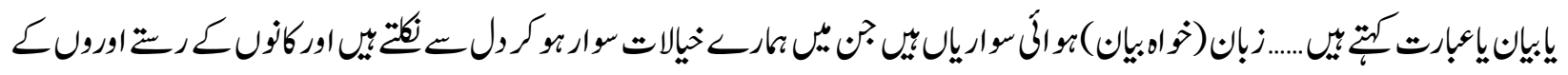

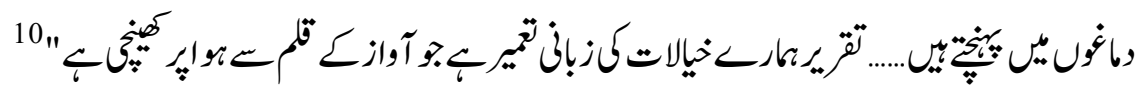

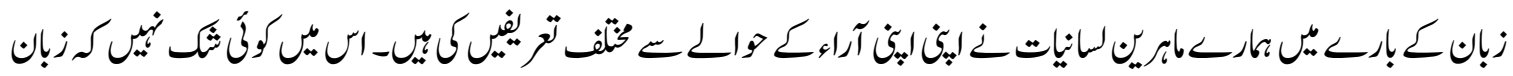

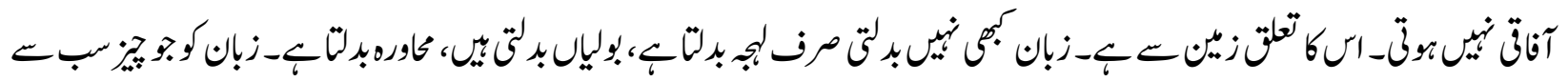

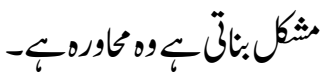

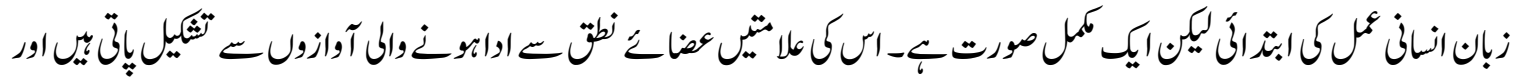

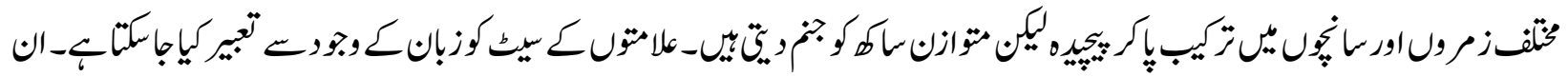

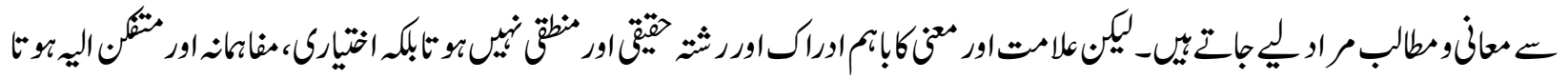

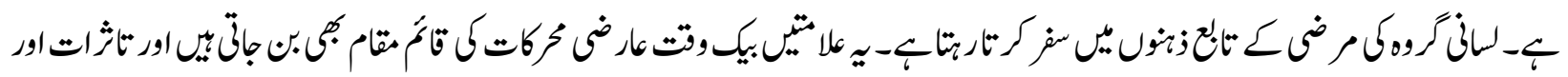

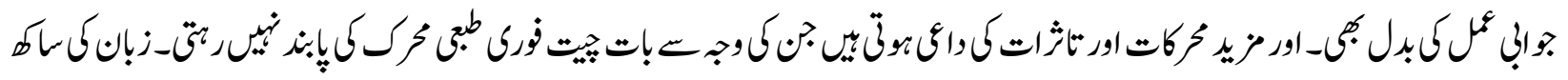




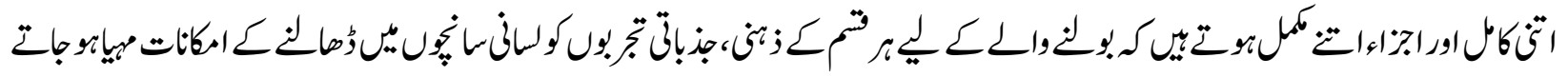

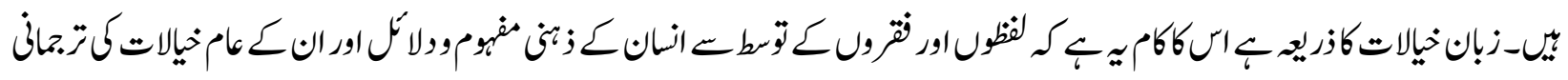

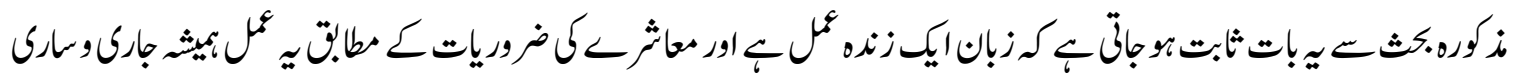
s 论标放 